\title{
A IMPORTÂNCIA DO ESTÁGIO SUPERVISIONADO NA FORMAÇÃO DO PROFISSIONAL DE ENFERMAGEM
}

\author{
Matheus Mendes Pascoal ${ }^{1}$ \\ Vanieli de Souza ${ }^{2}$
}

RESUMO: Este artigo tem por finalidade responder a questão norteadora: qual a importância do Estágio Supervisionado na formação do profissional de enfermagem? Justifica-se o estudo desse tema para compreender a relevância na realização do estágio em vários campos e áreas de atuação do profissional de enfermagem, que vão desde atenção básica até o atendimento em Unidades de Terapia Intensiva, onde nos últimos anos da graduação, a maior parte é destinada a realização de estágios, e o trabalho desenvolvido é fundamental para atuação prática eficiente no exercício da profissão e escolha da área que o profissional de enfermagem irá atuar. Para tanto, tem-se por objetivo geral analisar a importância do Estágio Supervisionado para formação do profissional de enfermagem, e como objetivos específicos apresentar sobre os campos de atuação do profissional de enfermagem, descrever sobre o Estágio Supervisionado na Enfermagem, e pôr fim a importância da teoria e prática para atuação profissional. A metodologia utilizada neste artigo trata-se de uma revisão integrativa, onde o método de pesquisa para incorporação é o de evidências na saúde destacando a área da enfermagem, utilizou-se de pesquisas em artigos científicos. Após o levantamento e coleta dos dados, foi elaborado um quadro com os principais resultados dos artigos estudados, com o nome dos autores e ano de publicação para melhor entendimento e organização, tornando-se possível atingir os objetivos geral e específico, bem como responder a questão norteadora, onde foi possível concluir que o papel do estágio é fundamental, pois coloca o acadêmico em contato com diversas situações do cotidiano.

Palavras-chaves: Estágio. Saúde. Enfermagem.

\section{INTRODUÇÃO}

O profissional de enfermagem desempenha um papel fundamental no cuidado do paciente, devendo prestar uma assistência de qualidade, deve conhecer todas as áreas de atuação e como deve ser sua tomada de decisão frente aos desafios do cotidiano

\footnotetext{
${ }^{1}$ Graduando em Enfermagem-Centro Universitário Integrado, Editor Júnior da SaBios, Membro da LAESM e LADCIST.E-mail:matheus_mendesis@hotmail.com.

${ }^{2}$ Graduanda em Enfermagem-Centro Universitário Integrado, Membro da LADCIST e LAACENF.
} 
profissional, compreendendo assim a importância dos estágios durante a graduação (FILHO, 20I0).

O papel do Estágio Supervisionado vai muito além da prática da teoria aprendida nas universidades, ela faz com que o aluno reflita sobre o seu papel enquanto profissional, bem como a humanização do seu trabalho ao tratar um paciente (FILHO, 20Io).

Nesse sentido, o estágio contribui não somente para a formação teórica prática, mas no desenvolvimento de ações e posturas que o profissional deve ter quando formado, e ainda como proceder em situações que lhe são colocadas no atendimento ao paciente, que não são descritas na teorias, como intercorrências, e também como sua atuação possibilita uma transformação na sociedade e sua contribuição na recuperação ou no cuidado do indivíduo, e ainda no estágio é possível o desenvolvimento do campo profissional que melhor se identifica, buscando assim se especializar nesse campo (PEREIRA; LEITE, 2017).

Dentro desse âmbito, vale destacar que a educação continuada da equipe, facilitará a busca e o aprendizado de novas habilidades e ciências, adaptando-se a realidade com a teoria, levantando-se como hipótese ao problema inicial, que a compaixão e a humanização tornam-se indispensáveis no processo saúde-doença, e por meio da prática é possível verificar esses aspectos e realizar levantamento de hipóteses em relação ao paciente (MARTINS; ALMEIDA, 2016).

Durante a graduação, o enfermeiro tem contato com uma infinidade de teorias significativa e fundamentais para sua atuação prática, bem como o gerenciamento das suas atividades e organização, uma vez que precisa estabelecer rotinas, cronogramas para um melhor atendimento ao paciente, sendo fundamental para o cuidado de forma qualificado (ESTEVES et. al.;2016).

Para a concretização deste artigo será realizado um estudo de revisão integrativa que inclui a análise de pesquisas relevantes que dão suporte para a tomada de decisão e a melhoria da prática clínica, possibilitando a síntese do estado do conhecimento de um determinado assunto, além de apontar lacunas do conhecimento que precisam ser preenchidas com a realização de novos estudos. Conforme cita Broome (200o, p.34): 
o processo de elaboração da revisão integrativa se inicia com a definição de um problema e a formulação de uma hipótese ou questão de pesquisa que apresente relevância para a saúde e enfermagem. $O$ assunto deve ser definido de maneira clara e específica, sendo que a objetividade inicial predispõe todo o processo a uma análise direcionada e completa, com conclusões de fácil identificação e aplicabilidade. Uma vez que a questão de pesquisa é bem delimitada pelo revisor, os descritores ou palavraschaves são facilmente identificados para a execução da busca dos estudos. (BROOME, 2000)

$\mathrm{Na}$ revisão integrativa se estabelece que, critérios de inclusão e exclusão do conteúdo devem ser definidos, para que não se torne um estudo cansativo e longo. Para a realização da pesquisa serão percorridas seis etapas: identificação do tema e seleção da questão de pesquisa; estabelecimento dos critérios de inclusão/exclusão; identificação dos estudos pré-selecionados e selecionados; categorização dos estudos selecionados; análise e interpretação dos resultados; e apresentação da revisão/síntese do conhecimento. (BOTELHO et al, 20II).

Definiu-se, portanto, a seguinte questão norteadora: Qual o parecer que se apresenta nas produções científicas em relação ao Estágio Curricular de enfermagem para o processo de formação de enfermeiros.

Após esta etapa será preciso realizar uma categorização dos estudos, ou seja, separar o que são de relevância e que auxiliaram a responder à questão norteadora.

A estruturação científica do trabalho se deu através de algumas questões que direcionaram a busca dos artigos, que ocorreram entre maio e julho de 2020, nas bases de dados Scielo, Lilacs, Medline e Research Gate, utilizando os seguintes descritores em Ciências da Saúde (DeCS): estágio supervisionado, enfermagem e atuação prática.

Os critérios de inclusão utilizados para estabelecer a amostra foram artigos de pesquisa, revisões e um relato de experiência que abordam a importância do estágio supervisionado em profissionais de enfermagem. Foram excluídos do estudo artigos em inglês, espanhol e que não estão inclusos em um período de cinco anos.

Os artigos encontrados sobre o tema foram acessados e lidos na íntegra para avaliação de forma crítica com base nas indagações levantadas na questão norteadora. 
Depois de localizado e lidas às publicações, foi realizado o fichamento incluindo os dados de ano, autor, título, objetivo e resumo.

Os artigos foram colocados em um quadro (quadro I) expondo suas fontes de pesquisa cientifica, e os resultados foram analisados e descritos a partir das unidades temáticas, para tal foi construída um segundo quadro (quadro 2) contendo os dados.

Enfim, justifica-se o estudo desse tema para compreender a relevância na realização do estágio em vários campos e áreas de atuação do profissional de enfermagem, que vão desde atenção básica até o atendimento em Unidades de Terapia Intensiva, onde nos últimos anos da graduação, a maior parte é destinada a realização de estágios, e o trabalho desenvolvido é fundamental para atuação prática eficiente no exercício da profissão e escolha da área que o profissional de enfermagem irá atuar.

Frente ao exposto, buscaremos analisar a importância do Estágio Supervisionado para formação do profissional de enfermagem.

\section{RESULTADOS E DISCUSSOES}

Seguindo a estratégia definida, a busca bibliográfica resultou em 31 artigos. Destes 3I artigos, Io foram escolhidos, os quais focavam a respeito do tema e foram inseridos no presente estudo.

Após leitura minuciosa de todos os artigos, foi possível selecionar informações, que serviram para identificá-los com a temática abordada, método de pesquisa utilizado, principais problemas encontrados, resultados e conclusões.

Os artigos científicos incluídos nesta revisão estão descritos no quadro r e quadro 2, as quais foram avaliadas e descritas a seguir nos critérios apresentados anteriormente.

Quadro I- Distribuição da variável fonte de publicação onde foi realizada a coleta de dados dos artigos publicados em periódicos nacionais no período de 2015 a 2020.

\begin{tabular}{|c|c|c|c|}
\hline Variáveis & $\begin{array}{c}\mathrm{N}^{\circ} \text { de } \\
\text { publicações } \\
\text { selecionadas }\end{array}$ & $\begin{array}{c}\mathrm{N}^{\circ} \text { de } \\
\text { publicações } \\
\text { selecionadas }\end{array}$ & $\%$ \\
\cline { 3 - 5 } & Fonte de Publicação & \% & \\
\hline
\end{tabular}




\begin{tabular}{|c|c|c|c|}
\hline Scielo & I2 & 05 & $50 \%$ \\
\hline Lilacs & 8 & 02 & $20 \%$ \\
\hline Medline, & 6 & oI & 10\% \\
\hline Statistical Package for the Social Sciences & 02 & oI & I0\% \\
\hline BVS & 03 & 0I & 100\% \\
\hline Total & 31 & 10 & \\
\hline
\end{tabular}

Fonte: Autoria nossa.

Quadro 2 - Síntese dos artigos sobre o Estágio Supervisionado na formação do profissional de Enfermagem, segundo ano de publicação, autores, título e resumo dos trabalhos.

\begin{tabular}{|c|c|c|c|c|}
\hline Ano & Autores & Titulo & Objetivo & Resultados \\
\hline 2015 & $\begin{array}{l}\text { Wana Yeda } \\
\text { Paranhos; } \\
\text { Adriano } \\
\text { Aparecido } \\
\text { Bezerra } \\
\text { Chaves; } \\
\text { Marcos } \\
\text { Antônio da } \\
\text { Eira Frias; } \\
\text { Maria } \\
\text { Madalena } \\
\text { Januário } \\
\text { Leite }\end{array}$ & $\begin{array}{l}\text { Análise do } \\
\text { desempenho dos } \\
\text { estudantes de } \\
\text { enfermagem no } \\
\text { ensino por } \\
\text { competências e } \\
\text { no ensino para } \\
\text { compreensão }\end{array}$ & $\begin{array}{lr}\text { Analisar } & \mathrm{o} \\
\text { desempenho } & \text { dos } \\
\text { estudantes } & \text { da } \\
\text { disciplina } & \text { Estágio } \\
\text { Curricular } & \\
\text { Supervisionado } & \text { do } \\
\text { projeto pedagógico } \\
\text { baseado } & \text { em } \\
\text { Competências } & \\
\text { (currículo A) } & \text { dos } \\
\text { estudantes } & \text { do } \\
\text { projeto pedagógico } \\
\text { na perspectiva do } \\
\text { Ensino } \\
\text { Compreensão } & \text { para } \\
\text { (currículo B). }\end{array}$ & $\begin{array}{l}\text { A avaliação do desempenho dos } \\
\text { estudantes do currículo A não teve } \\
\text { diferença em relação à média geral dos } \\
\text { estudantes do currículo B. Os estudantes } \\
\text { do A mostraram melhor desempenho em } \\
\text { relação ao B na unidade de terapia } \\
\text { intensiva e no tópico práticas pedagógicas, } \\
\text { e os do B nos tópicos bases } \\
\text { comportamentais e atitudinais e gestão. } \\
\text { Os estudantes que são técnicos de } \\
\text { enfermagem têm desempenho melhor e os } \\
\text { que trabalham à tarde têm melhores notas. } \\
\text { Conclusão: Não foi comprovada a } \\
\text { hipótese de que os estudantes da disciplina } \\
\text { Estágio Curricular Supervisionado do } \\
\text { currículo por compreensão (B) tem } \\
\text { melhor desempenho que os estudantes do } \\
\text { currículo por competências (A). A } \\
\text { formação como técnico de enfermagem e } \\
\text { turno de trabalho foram variáveis que } \\
\text { interferiram no desempenho dos alunos } \\
\text { independentemente do tipo de currículo. } \\
\text { Durante o estudo houve a possibilidade de } \\
\text { analisar os instrumentos de avaliação de } \\
\text { desempenho dos estudantes, bem como o } \\
\text { preenchimento pelos docentes, } \\
\text { constatando-se que há necessidade de } \\
\text { melhor estruturação na avaliação de } \\
\text { desses. }\end{array}$ \\
\hline
\end{tabular}




\begin{tabular}{|c|c|c|c|c|}
\hline 2016 & $\begin{array}{l}\text { Karina } \\
\text { Raquel } \\
\text { Modesto } \\
\text { Martins; } \\
\text { Teógenes de } \\
\text { Oliveira; } \\
\text { André Luiz } \\
\text { Dantas } \\
\text { Bezerra; } \\
\text { Petrônio } \\
\text { Souto } \\
\text { Gouveia } \\
\text { Filho; } \\
\text { Elzenir } \\
\text { Pereira de } \\
\text { Oliveira } \\
\text { Almeida; } \\
\text { Milena } \\
\text { Nunes Alves } \\
\text { de Sousa. }\end{array}$ & $\begin{array}{l}\text { Perspectivas de } \\
\text { acadêmicos de } \\
\text { enfermagem } \\
\text { diante dos } \\
\text { Estágios } \\
\text { Supervisionados }\end{array}$ & 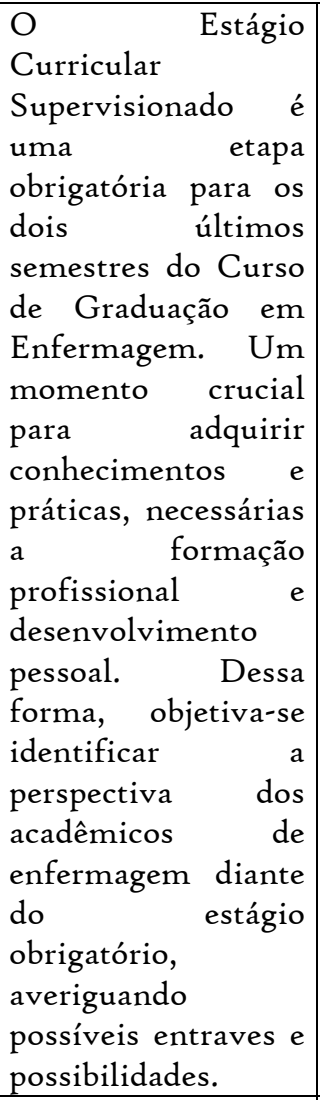 & $\begin{array}{l}\text { Os dados obtidos mostraram que a } \\
\text { principal vantagem do estágio foi à } \\
\text { aquisição de conhecimentos. Porém, a } \\
\text { maioria encontra dificuldades } \\
\text { relacionadas ao distanciamento entre a } \\
\text { teoria e a prática; e que a experiência do } \\
\text { estágio é insuficiente para formação } \\
\text { profissional. A percepção dos alunos sobre } \\
\text { o estágio tem pontos positivos e negativos. } \\
\text { Portanto as propostas sugeridas pelos } \\
\text { estudantes para melhorias do estágio } \\
\text { supervisionado, devem ser avaliadas pela } \\
\text { instituição, necessitando parande de } \\
\text { implementaçôes para solucionar os } \\
\text { problemas encontrados. }\end{array}$ \\
\hline 2017 & $\begin{array}{l}\text { Larissa } \\
\text { Sapucaia } \\
\text { Ferreira } \\
\text { Esteves, } \\
\text { Isabel } \\
\text { Cristina } \\
\text { Kowal Own } \\
\text { CunhaI, } \\
\text { Elena } \\
\text { BohomolI, } \\
\text { Elaine } \\
\text { Cristina } \\
\text { Negri }\end{array}$ & $\begin{array}{l}\text { O estágio } \\
\text { curricular } \\
\text { supervisionado } \\
\text { na graduação em } \\
\text { enfermagem: } \\
\text { revisão } \\
\text { integrativa. }\end{array}$ & $\begin{array}{lr}\text { Analisar } & \text { as } \\
\text { evidências } & \\
\text { disponíveis } & \text { na } \\
\text { literatura sobre } & \text { as } \\
\text { contribuições } & \text { do } \\
\text { Estágio Curricular } \\
\text { Supervisionado na } \\
\text { formação } & \text { em } \\
\text { enfermagem no } \\
\text { Brasil e os métodos } \\
\text { de ensino- } \\
\text { aprendizagem } \\
\text { empregados. }\end{array}$ & $\begin{array}{l}\text { Dos } 4.699 \text { artigos consultados, I4 } \\
\text { atenderam aos critérios de inclusão. A } \\
\text { análise desses estudos revelou três } \\
\text { categorias temáticas: a compreensão } \\
\text { acerca do papel do Estágio Curricular } \\
\text { Supervisionado; os processos de ensino- } \\
\text { aprendizagem empregados; e suas } \\
\text { contribuições para a formação do } \\
\text { enfermeiro. Considerações finais: é um } \\
\text { elemento fundamental na formação } \\
\text { acadêmica, pois, dependendo da } \\
\text { organização didático-pedagógica, } \\
\text { possibilita a ressignificação dos } \\
\text { conhecimentos adquiridos ao longo do } \\
\text { curso e concretiza as competências } \\
\text { profissionais. Os métodos de ensino- } \\
\text { aprendizagem estão estruturados pela } \\
\text { pedagogia crítica, sendo as metodologias } \\
\text { ativas as principais escolhas dos autores. }\end{array}$ \\
\hline 2017 & $\begin{array}{l}\text { Zayre } \\
\text { Gizelle } \\
\text { Oliveira; } \\
\text { Gabriel } \\
\text { Souza }\end{array}$ & $\begin{array}{ll}\text { Relato } & \text { de } \\
\text { Experiência: } & \\
\text { Contribuição } & \text { do } \\
\text { Estágio } & \\
\text { Curricular } & \text { da }\end{array}$ & $\begin{array}{lr}\text { Relatar } & a \\
\text { experiência } & \text { dos } \\
\text { alunos da disciplina } \\
\text { Enfermagem } & \text { em } \\
\text { Gestão } & \text { Hospitalar }\end{array}$ & $\begin{array}{l}\text { Foi possível compreender que o } \\
\text { gerenciamento não deve e não pode ser } \\
\text { visto como uma função isolada ao } \\
\text { processo de enfermagem, pois para } \\
\text { realizar qualquer procedimento se faz }\end{array}$ \\
\hline
\end{tabular}




\begin{tabular}{|c|c|c|c|c|}
\hline & $\begin{array}{l}\text { Santos; } \\
\text { Afonso } \\
\text { Ferreira } \\
\text { Lima Neto; } \\
\text { Yasmin da } \\
\text { Silva Soares; } \\
\text { Ivna Helena } \\
\text { Machado } \\
\text { Figueiredo. }\end{array}$ & $\begin{array}{l}\text { disciplina de } \\
\text { Enfermagem em } \\
\text { Gestão } \\
\text { Hospitalar para } \\
\text { os acadêmicos } \\
\text { do } 7^{\circ} \text { período de } \\
\text { enfermagem }\end{array}$ & $\begin{array}{l}\text { na vivência do } \\
\text { estágio curricular. }\end{array}$ & $\begin{array}{l}\text { necessário pensar, avaliar a ação a ser } \\
\text { desenvolvida, providenciar os recursos } \\
\text { necessários à realização da atividade, } \\
\text { preparar o ambiente para tal, e que os } \\
\text { conhecimentos de gerência sejam } \\
\text { colocados em prática, tendo como certeza } \\
\text { que as informações obtidas no decorrer da } \\
\text { formação acadêmica são os instrumentos } \\
\text { que nos permitem atuação no processo de } \\
\text { tomada de decisão e gerência. }\end{array}$ \\
\hline 2018 & $\begin{array}{l}\text { Rosângela } \\
\text { Vidal de } \\
\text { Negreiros; } \\
\text { Vanessa } \\
\text { Cristine } \\
\text { Batista de } \\
\text { Lima }\end{array}$ & $\begin{array}{l}\text { A importância } \\
\text { do } r \text { Estágio } \\
\text { Supervisionado } \\
\text { para r o } \\
\text { acadêmico de } \\
\text { enfermagem no } \\
\text { hospital: } \\
\text { compartilhando } \\
\text { experiências } \\
\text { vivenciadas com } \\
\text { a equipe de } \\
\text { trabalho }\end{array}$ & $\begin{array}{lr}\text { Compartilhar } & \text { a } \\
\text { experiência } & \text { do } \\
\text { estágio } & \\
\text { supervisionado } & \\
\text { enfatizando } & \text { a } \\
\text { importância } & \text { do } \\
\text { trabalho em equipe } \\
\text { no sistema } \\
\text { hospitalar. }\end{array}$ & $\begin{array}{l}\text { O funcionamento do sistema hospitalar } \\
\text { depende do bom andamento de todos os } \\
\text { serviços prestados, no entanto para que } \\
\text { haja qualidade nos serviços existe um } \\
\text { fator preponderante que é a concretização } \\
\text { do trabalho em equipe, é de suma } \\
\text { importância que o acadêmico desenvolva } \\
\text { competências que favoreça a sintonia do } \\
\text { trabalho em equipe, favorecendo para que } \\
\text { a assistência seja efetivada de maneira } \\
\text { coerente e uniforme, associando as } \\
\text { possibilidades propostas pela literatura } \\
\text { com a realidade cotidiana da instituição. }\end{array}$ \\
\hline 2018 & $\begin{array}{l}\text { Jorge Luiz } \\
\text { Rigobello; } \\
\text { Andrea } \\
\text { Bernardes; } \\
\text { André } \\
\text { Almeida de } \\
\text { Moura; } \\
\text { Ariane } \\
\text { Cristina } \\
\text { Barboza } \\
\text { Zanetti; } \\
\text { Wilza Carla } \\
\text { Spiri; } \\
\text { Carmen } \\
\text { Silvia } \\
\text { Gabriel }\end{array}$ & $\begin{array}{l}\text { Estágio } \\
\text { Curricular } \\
\text { Supervisionado } \\
\text { e } \\
\text { desenvolviment } \\
\begin{array}{lr}\text { competências } \\
\text { gerenciais: }\end{array} \\
\begin{array}{lr}\text { visão } \\
\text { egressos, } \\
\text { graduandos } \\
\text { docentes }\end{array}\end{array}$ & 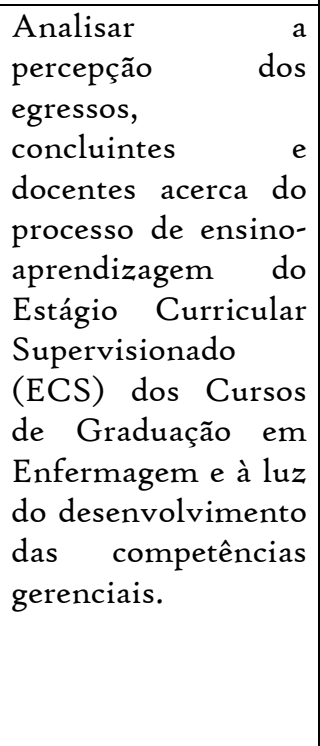 & $\begin{array}{l}\text { Emergiram quatro categorias temáticas } \\
\text { acerca desse processo e do } \\
\text { desenvolvimento das competências } \\
\text { gerenciais, evidenciando: o papel } \\
\text { fundamental do enfermeiro supervisor no } \\
\text { ECS; a necessidade de maior presença dos } \\
\text { docentes; quanto às competências } \\
\text { gerenciais, os sujeitos enfatizaram } \\
\text { liderança, gestão de recursos e } \\
\text { desempenho das funções burocráticas } \\
\text { como ens } \\
\text { essenciais. Considerações finais: O ECS } \\
\text { constitui um ambiente propício ao } \\
\text { aprendizado da profissão } \\
\text { desenvolvimento de competências } \\
\text { gerenciais, entretanto, faz-se necessário } \\
\text { maior articulação entre as instituições de } \\
\text { ensino e locais da prática do ECS. }\end{array}$ \\
\hline 2018 & $\begin{array}{l}\text { Luzimar } \\
\text { Rangel } \\
\text { Moreira; } \\
\text { Aldenir } \\
\text { Teotônio } \\
\text { Siqueira; } \\
\text { Paula Torres }\end{array}$ & $\begin{array}{l}\text { Percepção do } \\
\text { enfermeiro } \\
\text { acerca } \\
\text { formação } \\
\text { acadêmica para o } \\
\text { exercício }\end{array}$ & 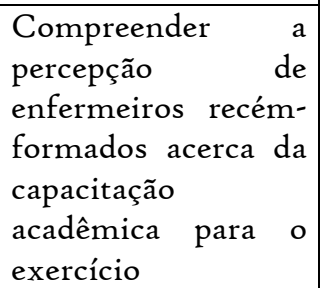 & $\begin{array}{l}\text { O estágio aparece como um importante } \\
\text { meio pelo qual o discente consegue suprir } \\
\text { as carências relacionadas à prática } \\
\text { profissional e vivenciar a realidade no } \\
\text { campo de atuação. }\end{array}$ \\
\hline
\end{tabular}




\begin{tabular}{|c|c|c|c|c|}
\hline & $\begin{array}{l}\text { Santos; } \\
\text { Vinicius } \\
\text { Nascente } \\
\text { Ladislau }\end{array}$ & profissional & profissional. & \\
\hline 2019 & $\begin{array}{l}\text { Lourdes } \\
\text { Missio; } \\
\text { Fabiane Melo } \\
\text { HeinenGana } \\
\text { ssin; } \\
\text { Marcia } \\
\text { Maria Ribera } \\
\text { Lopes } \\
\text { Spessoto; } \\
\text { Pâmela Luiza } \\
\text { Araujo } \\
\text { Gomes }\end{array}$ & $\begin{array}{l}\text { Estágio } \\
\text { curricular } \\
\text { supervisionado: } \\
\text { vivências na } \\
\text { licenciatura em } \\
\text { enfermagem }\end{array}$ & $\begin{array}{l}\text { Apresentar os } \\
\text { aspectos do curso de } \\
\text { licenciatura a partir } \\
\text { das vivencias dos } \\
\text { discentes e docentes } \\
\text { do curso de } \\
\text { graduação em } \\
\text { enfermagem da } \\
\text { Universidade } \\
\text { Estadual do Mato } \\
\text { Grosso do Sul. }\end{array}$ & $\begin{array}{l}\text { O professor de estágio curricular } \\
\text { supervisionado precisa acompanhar os } \\
\text { movimentos de mudanças tanto do } \\
\text { contexto da saúde como da educação, para } \\
\text { direcionar seus alunos estagiários à } \\
\text { formação adequada as necessidades } \\
\text { demandadas desses setores. }\end{array}$ \\
\hline 2019 & $\begin{array}{l}\text { Livia Maria } \\
\text { da Silva, } \\
\text { Tuanny } \\
\text { Caroline } \\
\text { Pereira de } \\
\text { Santana, } \\
\text { LaiseRisalva } \\
\text { Farias } \\
\text { Gouveia da } \\
\text { Silva, Leticia } \\
\text { Monteiro } \\
\text { Rocha, } \\
\text { Camilla } \\
\text { Talita Silva } \\
\text { Canhoto, } \\
\text { Karoline } \\
\text { Lima Dantas, } \\
\text { Ana Cristina } \\
\text { Farah Abdon } \\
\text { da Silva, } \\
\text { Eliana } \\
\text { Valetim da } \\
\text { Silva, Maria } \\
\text { Inês Bezerra } \\
\text { de Melo, } \\
\text { Reneide } \\
\text { Muniz da } \\
\text { Silva, Maria } \\
\text { Cristina dos } \\
\text { Santos }\end{array}$ & $\begin{array}{l}\text { Estágio } \\
\text { curricular } \\
\text { supervisionado: } \\
\text { dificuldades e } \\
\text { perspectivas } \\
\text { vivenciadas por } \\
\text { acadêmicos de } \\
\text { enfermagem }\end{array}$ & \begin{tabular}{lr} 
Descrever & as \\
principais & \\
dificuldades & e \\
possibilidades & \\
vivenciadas pelos \\
acadêmicos \\
enfermagem no \\
exercício do estágio \\
curricular \\
supervisionado nas \\
\multicolumn{2}{l}{ unidades de saúde. }
\end{tabular} & $\begin{array}{l}\text { Os dados obtidos na pesquisa mostram } \\
\text { que a principal vantagem do estágio } \\
\text { supervisionado foi à aquisição e o } \\
\text { aprimoramento de conhecimentos e } \\
\text { habilidades, porém, a maioria dos } \\
\text { estudantes encontraram algumas } \\
\text { dificuldades, relacionadas a } \\
\text { distanciamento entre a metodologia } \\
\text { teórica e prática, associado a experiência } \\
\text { do estágio ser insuficiente para formação } \\
\text { profissional. Conclusão: Embora seja } \\
\text { visível os desafios enfrentados pelos } \\
\text { acadêmicos de enfermagem durante sua } \\
\text { vivência frente ao estágio supervisionado, } \\
\text { esse momento é promissor de experiências } \\
\text { profissionais, as quais visam fortalecer o } \\
\text { processo de ensino-aprendizagem. } \\
\text { Entretanto, há necessidade de propostas } \\
\text { voltadas à melhoria do referido estágio. }\end{array}$ \\
\hline
\end{tabular}




\begin{tabular}{|c|c|c|c|c|}
\hline & $\begin{array}{l}\text { Figueira, } \\
\text { Rutheanne } \\
\text { Melo } \\
\text { Siqueira, } \\
\text { Mirella } \\
\text { Raquel } \\
\text { Romão } \\
\text { Martins , } \\
\text { Suzana Lins } \\
\text { da Silva, } \\
\text { Carina } \\
\text { Ribeiro de } \\
\text { Oliveira }\end{array}$ & & & \\
\hline 2020 & $\begin{array}{l}\text { Romulo da } \\
\text { Silva Viana; } \\
\text { Ronaldo } \\
\text { Caetano } \\
\text { Barboza; } \\
\text { Eduardo } \\
\text { Shimoda. }\end{array}$ & $\begin{array}{l}\text { A importância } \\
\text { do Estágio } \\
\text { Supervisionado } \\
\text { para a formação } \\
\text { do profissional } \\
\text { técnico em } \\
\text { enfermagem: } \\
\text { análise de } \\
\text { satisfação dos } \\
\text { alunos de uma } \\
\text { instituição } \\
\text { federal de ensino }\end{array}$ & $\begin{array}{lr}\text { Identificar rr os } \\
\text { pontos a } & \text { serem } \\
\text { melhorados } & \text { no } \\
\text { Estágio } & \\
\text { Supervisionado } \\
\text { obrigatório r do } \\
\text { Curso Técnico em } \\
\text { Enfermagem do IFF } \\
\text { Campus Campo } \\
\text { Guarus. }\end{array}$ & $\begin{array}{l}\text { Os resultados apontaram i4 quesitos que } \\
\text { precisam ser melhorados no curso de } \\
\text { enfermagem, sendo os que precisam ser } \\
\text { melhorados apontados pelos alunos em } \\
\text { formação são: condições das unidades de } \\
\text { estágio para a prática; possibilidade de } \\
\text { interferir na dinâmica do processo de } \\
\text { enfermagem; possibilidade; de fato, de } \\
\text { executar as atividades profissionais. }\end{array}$ \\
\hline
\end{tabular}

Fonte: Autoria nossa.

Com relação ao ano de publicação dos escolhidos, foram publicados entre 2015 e 2019. Com relação aos títulos dos artigos todos falam sobre o Estagio Supervisionado e a atuação do profissional de enfermagem.

O Estágio Supervisionado é abordado em todos os artigos selecionados, ficando clara a sua contribuição para formação do profissional de enfermagem, sendo que todas as áreas que o profissional atua são importantes para reflexão da prática e atuação junto ao paciente e a instituição no qual está realizando o estágio, podendo compreender na prática, como deve agir perante situação em que não foi explorado na teoria, é ter o olha crítico e por meio do conhecimento já obtido, traçar estratégias de atuação, dentre outras e muitas contribuições em que o estágio traz para o acadêmico durante a sua formação. 
Estudos sobre o Estágio Supervisionado no curso de enfermagem, apontam a importância das metodologias utilizadas para o processo de ensino-aprendizagem, bem como atuação em diversas áreas da saúde, uma vez que no momento da atuação o profissional de enfermagem pode escolher a área que irá atuar, e por isso ter o contato e realizar o estágio em diversas áreas é imprescindível.

Nos estudos de Paranhos et. al (2015), os autores dividem a teoria e a pratica em dois currículos, nomeados de competência e prática educativa, sendo que no primeiro são analisados a capacidade do aluno na mobilização de um conjunto de recursos como: recursos ou atributos cognitivos, afetivos e psicomotores, relações, valores, postura, cultura, princípios éticos, destrezas e habilidades para solucionar com pertinência e eficácia as situações profissionais, e na prática educativa tem o intuito é de verificar na pratica o entendimento do alunos sobre os conceitos, e também como se comportaram diante das mais diversas atuais do cotidiano do enfermeiro.

Estes mesmos estudos identificaram que além do trabalho da faculdade e todo o corpo docente, o resultado do estágio depende do estagiário, do seu empenho, dedicação, interesse, o olhar crítico, questionar-se sempre, e o que faz o profissional se destacar é a busca constante por conhecimento e especialização na área que escolhe após sua formação, os estudos mostraram que o aluno tem maior desenvolvimento na teoria e maiores dificuldades na atuação prática.

$\mathrm{Na}$ comparação dos desempenhos dos estudantes do estágio curricular supervisionado do currículo baseado em competências e os do currículo modular baseado no ensino para compreensão, os primeiros mostraram melhor desempenho na unidade de terapia intensiva e práticas assistenciais e os segundo em bases comportamentais e atitudinais e gestão. Quanto à formação na área da saúde, os estudantes que são técnicos de enfermagem têm desempenho melhor dos que não têm formação na área da saúde (PARANHOS et. al, 2015, p. II9).

Conforme exposto, mesmo com carga horária extensa de estágios, o grupo de estudantes analisados apresentaram melhor desenvolvimento com competência em relação a prática educativa, e que técnicos de enfermagem que realizam processo operacionais no cotidiano e não possuem tanta teoria, apresentaram melhores resultados na atuação prática com os pacientes, demonstrando assim que o estágio é de extrema relevância, e se torna 
fator determinante durante a atuação do enfermeiro, pois após sua formação a junção da teoria e prática no seu trabalho serão dois eixos determinantes na profissão.

Nos estudos realizados por Martins et. al (2016), os autores apresentam os fatores que podem levar à um resultado ineficiente durante a realização dos estágios, sendo alguns dos pontos muitos alunos realizando o estágio em um mesmo local, onde o professor do estágio não consegue dar atenção e corrigir as falhas durante a realização do trabalho do estagiário, e também a resistência dos pacientes em serem atendidos por estagiários, são os principais fatores que fazem com que seja desfavorável aos alunos que esperam do estágio nos últimos períodos amplas oportunidades de expandir seus conhecimentos e realizar o que ainda não foi visto; para adquirir segurança frente ao mercado de trabalho.

Uma vez que a prática é um processo indiscutível para a qualidade do exercício do futuro profissional, pois sem a prática realizada com qualidade o aluno não estará preparado para o mercado de trabalho, e para isso atuar nas mais diversas situações do cotidiano do campo da enfermagem é ponto determinante na formação acadêmica.

Ainda segundo Martins et. al (2016) apresentam que:

Algumas dificuldades também são encontradas no estágio, em destaque a falta de cuidados práticos para o aperfeiçoamento da técnica e a pouca correlação com teoria, deixando, na visão dos alunos, insuficiente para formação profissional deles. Resultando-se em um ponto de confronto, devido à contradição das expectativas dos estudantes, que se traduz em inseguranças, como também ao entendimento de que estagiar é praticar, é unir o conhecimento teórico/prática, é vivenciar a realidade.

Demonstrando assim que, é preciso ter cuidado ao transmitir como deve ser a prática aos alunos, é preciso adoção de técnicas corretas e quando necessárias adaptadas a cada tipo de paciente, para que o aluno no momento da sua atuação profissional saiba como lidar com as mais diversas situações, e nem sempre na prática o que estudou na teoria é aplicável da mesma maneira para todos, e o estágio deve preparar o aluno para lidar com as mais diversas situações, e a faculdade deve estar atenta aos pontos positivos e negativos do estágio apontados pelos alunos, para uma melhora dos pontos negativos quando forem pertinentes, e com isso uma melhora da qualidade de ensino do estágio frente a formação completa do profissional de enfermagem. 
Oliveira et. al (2017) realizaram estudos para compreender como os alunos de enfermagem compreenderam em seu estágio o uso dos seus materiais a nível operacional, e a importância do aluno durante a realização do estágio compreender sobre os recursos financeiros e operacionais e como pode também atuar em outras áreas após formado, sendo uma dessas áreas de gestão hospitalar, por isso a vivência de múltiplas áreas durante o estágio é de suma importância para o aluno compreender sobre os aspectos de forma ampla após sua formação e assim escolher a área que melhor se identifica.

Segundo Esteves et. al (2018) o estágio é primordial para a formação do profissional de Enfermagem, para tornar-se um profissional atuante, crítico, curioso e construtor de conhecimento na sua área de atuação, aquele que não se restringe somente a teoria, que busca além, que questiona as metodologias adotadas, busca novos conhecimento, e ainda colabora para aguçar as faculdades de observação do futuro profissional, além de desenvolver a necessidade de buscar novos saberes de comunicação, flexibilidade e de tomada de decisão, uma vez que o estágio deve estar em constante atualizações, pois a prática e atuação é diferente para cada tipo de paciente atendido, por este fato que o estágio está mergulhado no campo da complexidade, e ainda o aluno deve ser induzido a pensar e refletir sobre sua prática e o que pode ainda melhorar em determinado procedimento, e propor soluções para problemas reais vivenciados.

Moreira et.al (2018) realizou um estudo para verificar a percepção dos estudantes de enfermagem sobre o estágio, e constatou-se que todos acreditam contribuir de forma significativa, fazendo durante a realização do mesmo, pois torna possível a vivencia da realidade da prática profissional antes mesmo da formação.

Nos estudos realizados por Negreiros e Lima (2018) as autoras descrevem que é por meio do estágio que o futuro enfermeiro (a) recebe a validação sobre o seu curso, uma vez que fica diante de diversos desafios e com auxílio do professor deve procurar solucionar, tirar dúvidas, prestando o melhor atendimento possível ao paciente, simulando algumas das muitas situações que podem desencadear na sua atuação prática.

O aluno pode contribuir para a melhora nos processos de estágios, apontando as dificuldades e facilidades encontradas no processo de estágio, apresentando o que pode ser 
incluso na teoria para uma formação completa, uma vez que muitas vezes o que foi vivenciado na prática pode não ter sido abordado na teoria, precisando assim as universidades acompanhar $e$ acolher os apontamentos em relação as dificuldades $e$ facilidades encontradas no campo de estágio, e outro fator determinante são as metodologias utilizadas na teoria e prática são determinantes para melhor desenvolvimento do aluno no processo de ensino-aprendizagem.

Em relação as práticas pedagógicas Esteves et. al (2018, p. 1.850) descrevem que:

As atividades simuladas antes do ECS garantem independência e autonomia durante o estágio. Pelo envolvimento ativo de docentes, enfermeiros de campo e serviços de saúde, o ECS oportuniza também o fortalecimento dos vínculos ensino-serviço-comunidade. Essas contribuições, como ferramenta de quebra de paradigmas de atenção e de formação em saúde, tornam-se realidade se o estudante for inserido precocemente nos serviços de saúde. Nestes cenários, os atores inseridos no desenvolvimento do ECS são peças fundamentais para a edificação de competências, tendo em vista que enfermeiras educadoras sejam elas docentes vinculadas ao ensino superior, ou enfermeiras que atuam nos campos de estágio nas instituições de saúde são as portadoras da profissão de enfermagem e têm a tarefa de assegurar que aos estudantes de enfermagem a competência para atuarem no cenário clínico-dinâmico (ESTEVES et. al 2018).

Apresentando, as contribuições que a professora docente do campo de estágio também é vista como um exemplo a seguir, e suas práticas influenciam o aprendizado do aluno, devendo o seu trabalho ser realizado pensado e desenvolvido da melhor maneira possível, para que o aluno atuando após formado consiga lembrar dos conceitos e exemplos abordados pela professora orientadora dos estágios, que tem grande contribuição na vida acadêmica e profissional do aluno, pois suas ações são relembradas pelo profissional.

Sobre as contribuições do enfermeiro supervisor Rigobello et. al (2018, s.p) descreve que:

[...] é tido, ou idealizado, como um padrão a ser seguido pelo estudante na atuação prática, podendo ser considerado um modelo profissional a ser alcançado. Desta forma, esse profissional deve ter consciência da sua importância e de seu papel enquanto referência para o graduando, bem 
como da responsabilidade atribuída à sua posição, fazendo-se necessário rever e atualizar seus conhecimentos (RIGOBELLO et al, 2018).

Conforme exposto, é por meio do exemplo do orientador e da condução dos ensinamentos no campo de estágio que são direcionados pelo professor que levará ao aluno a refletir sua prática, pensar criticamente, questionar sobre a prática e ainda ser um exemplo a ser seguido pelo aluno, e por isso deve estar em constante atualização, para que durante a prática adote metodologias recentes e que tenham relação com a teoria, e nos casos das intercorrências ou alunos consigam entender as atitudes tomadas pelo supervisor e qual o critério utilizado.

A prática ainda se torna indispensável no curso de formação, segundo Rigobello et. al (2018) pois o aluno tem contato com o campo real que irá atuar no futuro, além de troca de experiências com diversos profissionais que já atuam algum tempo na área, fazendo pensar e refletir criticamente de forma individual e grupal, com isso a não observância dessa interação implica em demasiado prejuízo para o estudante, uma vez que pode acarretar em uma formação acadêmica deficiente e comprometer, dessa maneira, o perfil do futuro profissional. Essa deficiência de integração evidencia um grande desafio a ser enfrentado pelos sujeitos envolvidos no Estágio Supervisionado.

Uma vez que o estágio é um dos momentos que o aluno tem a oportunidade de colocar em prática seus conhecimentos, sobre esse aspecto Silva et. al (2019, p. 09) apresentam que:

O Estágio Curricular Supervisionado tem um papel fundamental para o discente de enfermagem por ser o momento onde visa o desenvolvimento e aprimoramentos das competências teórico-práticas; onde se chega mais próximo do que se espera pós conclusão do curso. Momento esse que deveria lhe dar todo o aporte profissional para execução das tarefas assistências de enfermagem, tomada de decisões, gerenciamento de pessoas e conflitos (SILVA et. al 2019).

Nota-se as barreiras enfrentadas pelos alunos de enfermagem, quando são desenvolvidas atividades no estágio, no surgimento de dúvidas, de tomada de decisões que não foram vistas na teoria, compreendendo que nem sempre os estágios irão atender a demanda da teoria e que o aprendizado completo acontecerá com a vivência prática depois 
da formação, por isso é preciso uma integração do conteúdo teórico e prática, e também da articulação entre instituições de ensino e serviços de saúde para que, de fato, o princípio da integralidade seja incorporado na formação dos acadêmicos do curso de enfermagem, uma vez que é no momento do estágio, é preciso fortalecer o processo de ensino-aprendizagem, além de proporcionar uma visão mais realística sobre a sua atuação como futuros enfermeiros (SILVA et. al, 2019).

Para verificar a importância do curso de Licenciatura em Enfermagem, Missio et. al (2019) realizou um estudo com docentes e discentes do curso, verificando as experiências e as contribuições que a teoria traz para prática durante o estágio, o que constatou que o papel do professor orientador em instrumentalizar e vincular a teoria com a prática é de extrema relevância, pois precisa fazer o aluno compreender o que foi explorado na teoria, e ainda orientar como deve tomar decisões práticas que pode não ter vivenciado de forma ampla na teoria, demonstrando também a importância de professores capacitados para acompanhamento do estágio curricular obrigatório e direcionamento dos seus alunos.

Nos estudos de Viana et.al (2020) os autores realizaram estudos para apresentar os fatores que podem ser melhorados nos estágios na visão dos estudantes, ficando em primeiro lugar a estrutura da unidade de saúde, como equipamentos e materiais disponíveis suficientes para prática de cada estagiário, e ainda o poder da decisão na intervenção junto ao paciente, que muitas vezes realizam serviços divergentes em relação ao que contempla o currículo, como apenas preencher fichas, olhar prontuário ao invés de aplicar uma injeção, fazer pulsão e curativos, constatando que o estágio deve considerar a prática de forma efetiva e não apenas serviços menos complexos.

Portanto, nos artigos foi possível analisar que todos apontam a relevância do Estágio no desenvolvimento da prática, bem como os desafios constantes das universidades e acadêmicos, para atuação eficiente e de qualidade do futuro profissional de enfermagem.

\section{CONSIDERACÕES FINAIS}


Identificou-se que, o Estágio Supervisionado é fundamental para formação profissional do enfermeiro, pois coloca o aluno em contato com vivencias no cotidiano em que irá atuar quando formado, porém possui muitos desafios para essa atuação, sendo algumas das dificuldades enfrentadas número elevados de alunos nas turmas de estágio, situações que não foram vistas na teorias mas que são necessárias tomada de decisão no campo prática, verificou-se que os alunos possuem melhor desenvolvimento nas teorias em relação a prática, e verificou-se o quão importante é o papel do supervisor de campo, na adoção de metodologias que consigam atingir o objetivo do ensino-aprendizagem, da constante atualização de técnicas e conteúdo, e ainda transmissão de valores, do papel humanizador do enfermeiro, da arte do cuidado, demonstrando que atuação vai muito além das teorias, é um conjunto de valores éticos e morais.

Foram observados nos artigos selecionados, que existem estratégias diversas para a compreensão dos alunos da sua importância dentro do ambiente no qual atua, e vivenciar os diversos campo da enfermagem, fazendo refletir sobre atuação profissional, e também fazendo compreender em qual área possui maiores habilidades e também ter contato com profissionais de enfermagem que já atuam a determinado tempo, e trocar experiências, isso se torna fundamental para a formação do enfermeiro.

Verificou-se nos artigos selecionados que todos foram unânimes em apresentar sobre a importância do Estágio na formação do enfermeiro, mas também apontaram os principais desafios enfrentados pelos profissionais após sua formação, desafios como tomada de decisões em relação a um procedimento a ser realizado que não visto na prática, a pensar criticamente que depende da forma de condução do estágio não faz com que o aluno pense criticamente, e também demonstrou-se que a qualidade na formação do indivíduo depende muito mais do acadêmico do que do aluno, de questionar-se, ser curioso, ampliar os conhecimentos sobre assuntos, durante o estágio opinar, dar sugestões, procurar relacionar a prática com a teoria e sempre estar se atualizando.

Enfim, o presente estudo apresentou as contribuições e desafios do Estágio Supervisionado para formação do profissional de enfermagem, compreendendo as dificuldades após formado na atuação prática, e como deve ser a postura frente aos desafios 
da atuação, e que a qualidade da atuação depende do empenho e também dedicação do profissional, que as universidades dão a base e o contato com o campo de experiência porém a dedicação do aluno também são fundamentais para uma prática de qualidade no exercício da profissão.

\section{REFERÊNCIAS BIBLIOGRÁFICAS}

BERGHETTI, L.; FRANCISCATTO, L.H.G.; GETELINA, C.O. Formação do enfermeiro acerca do gerenciamento: entraves e perspectivas. Revista de Enfermagemdo Centro-Oeste Mineiro, 2019.

BROOME M. Influence of stress and nursing leadership on job satisfaction of pediatric intensive care unit nurses. Am J CritCare. 2000.

ESTEVES, L. S. F. CUNHA, I. C.K.O.; BOHOMOLL, E.; NEGRI; O estágio curricular supervisionado na graduação em enfermagem: revisão integrativa. RevBrasEnferm [Internet], v.71, 2018.

FILHO, A. P. O Estágio Supervisionado e sua importância na formação docente. Revista P@rtes. 2010.

MARTINS, K. R. M.; OLIVEIRA, T. BEZERRA, A.L.D.; FILHO, P.S.G.; ALMEIDA, E.P.O. SOUSA, M. N.A. Perspectivas de acadêmicos de enfermagem diante dos estágios supervisionados. C\&D-Revista Eletrônica da Fainor, Vitória da Conquista, v.9, n.I, p.5673, jan./jun. 2016

MISSIO, L.; GANASSIN, F.M.H.; SPESSOTO, M.M.R.L.; GOMES, P.L.A. Estágio Curricular Supervisionado: Vivências na licenciatura em enfermagem. Laplage em Revista (Sorocaba), vol.5, n.I, jan-abr. 2019.

MOREIRA, L.R.; SIQUEIRA, A.T.; SANTOS, P.T.; LADISLAU, V.N.Percepção do enfermeiro acerca da formação acadêmica para o exercício profissional. Revista de Enfermagem, v.2, n. 4, 2018.

NEGREIROS, R.V.; LIMA, V.C.B.; Importância do Estágio Supervisionado para o acadêmico de enfermagem no hospital: compartilhando experiências vivenciadas com a equipe de trabalho. Revista da Universidade Vale do Rio Verde, v.I6, n. 2, 2018.

OLIVEIRA, Z.G.; SANTOS, G.S.; LIMA NETO, A.F.; SOARES, Y.S.; FIGUEIREDO, I.H.M. Relato de Experiência: Contribuição do Estágio Curricular da disciplina de 
Enfermagem em Gestão Hospitalar para os acadêmicos do $7^{\circ}$ período de enfermagem. InternationalNursingCongress, May 9-12, 2017.

PARANHOS, W.Y.; CHAVES, A.P.B.; FRIAS, M.A.E.; LEITE, M.M.J. Análise do desempenho dos estudantes de enfermagem no ensino por competências e no ensino para compreensão.RevEscEnferm USP, n.I, v. 49,2015,

PEREIRA, E.Z. LEITE, F.H.O.M.; A importância da prática do Estágio Supervisionado no Curso de Graduação em Enfermagem. Revista de Trabalhos acadêmicos - Universo. Belo Horizonte, v. I, n.2, 2017.

SILVA, L.W.S. Arte na Enfermagem: iniciando um diálogo Reflexivo, Rev. Estudos de Psicologia, PUC-Campinas, v. 19, n. I, p. 37-48, jan./marc. 2005.

SILVA, L.M.D. et. al. Estágio curricular supervisionado: dificuldades e perspectivas vivenciadas por acadêmicos de enfermagem. Revista Eletrônica Acervo Saúde, Vol .Sup.18, 2019 .

VIANA, R.S.; BARBOZA, R.C.; SHIMODA, E. A importância do Estágio Supervisionado para a formação do profissional técnico em enfermagem: análise de satisfação dos alunos de uma instituição federal de ensino.Revista Cienfica da FMC. v.I5, n. I, 2020 . 